\title{
Extended Park's transformation for 2×3-phase synchronous machine and converter phasor model with representation of AC harmonics
}

\author{
Knudsen, Hans
}

Published in:

IEEE Transactions on Energy Conversion

Link to article, DOI:

$10.1109 / 60.372577$

Publication date:

1995

Document Version

Publisher's PDF, also known as Version of record

Link back to DTU Orbit

Citation (APA):

Knudsen, H. (1995). Extended Park's transformation for $2 \times 3$-phase synchronous machine and converter phasor model with representation of AC harmonics. IEEE Transactions on Energy Conversion, 10(1), 126-132. https://doi.org/10.1109/60.372577

\section{General rights}

Copyright and moral rights for the publications made accessible in the public portal are retained by the authors and/or other copyright owners and it is a condition of accessing publications that users recognise and abide by the legal requirements associated with these rights.

- Users may download and print one copy of any publication from the public portal for the purpose of private study or research.

- You may not further distribute the material or use it for any profit-making activity or commercial gain

- You may freely distribute the URL identifying the publication in the public portal 


\section{Extended Park's Transformation \\ for 2x3-phase Synchronous Machine \\ and \\ Converter Phasor Model \\ with Representation of AC Harmonics.}

\author{
NESA / SK Power Company \\ Hellerup, Denmark
}

\begin{abstract}
A model of the 2x3-phase synchronous machine is presented using a new transformation based on the eigenvectors of the stator inductance matrix. The transformation fully decouples the stator inductance matrix, and this leads to an equivalent diagram of the machine with no mutual couplings in the stator.

A consistent method is developed to determine model parameters from standard machine data.

A phasor model of the line commutated converter is presented. The converter model includes not only the fundamental frequency, but also any chosen number of harmonics without a represention of the single thy ristors.
\end{abstract}

Keywords - 2x3-phase synchronous machine model, extended Park transformation, parameter identification, converter phasor model, harmonic representation, S.M. commutating inductance.

\section{INTRODUCTION.}

In recent years the converter-fed $2 \times 3$-phase synchronous machine (fig.1) has been gaining importance as a high power drive with high and variable speed. Because of this growing industrial interest, the $2 \times 3$-phase machine has been the subject of many studies recently. However, there has not yet been developed a model of this machine which is valid in all situations, and where the stator circuits are completely decoupled. The advantages of such a model will be the same as the advantages gained from Park's two-reaction theory for 3-phase synchronous machines; i.e. a constant inductance matrix with a minimum number of mutual couplings.

94 SM 350-9 EC A paper recommended and approved by the IEEE Electric Machinery Committee of the IEEE Power Engineering Society for presentation at the IEEE/PES 1994 Summer Meeting, San Francisco, CA, July $24-28$, 1994. Manuscript submitted August 30, 1993; made available for printing June 14, 1994.
The Electric Power Engineering Department Technical University of Denmark, Lyngby, Denmark.

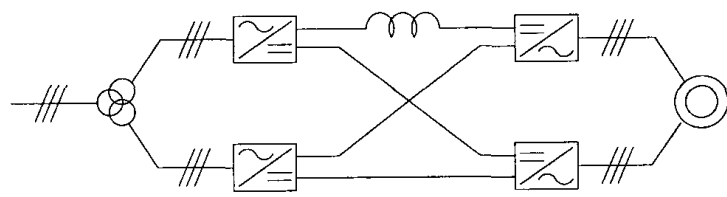

Fig. 1. 2x3-phase converter-fed synchronous machine.

Consequently the first topic of this paper is to present such a model.

Due to the state changes of the converter thyristors during commutations, it is necessary to use very small time steps during simulations in order to get a good representation of voltages and currents. Furthermore each time a thyristor changes state, the network admittance matrix is altered and has to be recalculated. These two factors lead to a vast time consumption during dynamic simulations. Today the only alternative is fundamental frequency phasor models, where all harmonics are ignored. It would therefore be desirable to have a phasor model, which includes the representation of any chosen number of harmonics, from no harmonics up to an infinite number of harmonics. The second topic of this paper is to present such a converter phasor model.

\section{MACHINE MODEL.}

\section{A. Machine description and equations.}

The $2 \times 3$-phase synchronous machine is designed as shown in fig.2, where the magnetic axes of the stator coils are shown. The two 3-phase systems are displaced $30^{\circ} \mathrm{el}$.

Using the same method as in [1] the self inductance of a stator coil or the mutual inductance of any two stator coils in an electric machine can be expressed as:

$$
M_{\text {SiSj }}=L_{\text {const }}+M_{B} \cos \left(2 \theta_{r}-s_{i}-s_{j}\right)
$$

where $\mathrm{L}_{\text {const }}$ is the constant part of the self or mutual inductance, $s_{x}$ is the angle of the magnetic axis of coil $x, \theta_{\mathrm{r}}$ is the instantaneous angle of the rotor, and $M_{B}$ is the rotor angle dependent mutual inductance. For self inductances the magnetic axes are equal $\left(s_{i}=s_{j}\right)$. All angles are measured relative to the magnetic axis of phase al as indicated in fig. 2 .

Arranging according to the two 3-phase systems, the constant part $\underline{L}_{\text {const }}$, of the stator inductance matrix $\underline{L}$ in (1), is: 


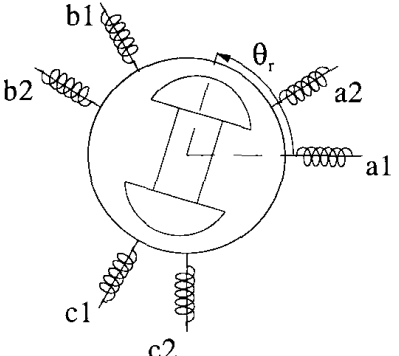

Fig. 2. $2 * 3$ phase synchronous machine

$\underline{L}_{c o n s t}=$\begin{tabular}{|l|l|l|l|l|l|}
\hline$L_{s}$ & $M_{1}$ & $M_{1}$ & $M_{2}$ & $-M_{2}$ & 0 \\
\hline$M_{1}$ & $L_{s}$ & $M_{1}$ & 0 & $M_{2}$ & $-M_{2}$ \\
\hline$M_{1}$ & $M_{1}$ & $L_{s}$ & $-M_{2}$ & 0 & $M_{2}$ \\
\hdashline$M_{2}$ & 0 & $-M_{2}$ & $L_{s}$ & $M_{1}$ & $M_{1}$ \\
\hline$-M_{2}$ & $M_{2}$ & 0 & $M_{1}$ & $L_{s}$ & $M_{1}$ \\
\hline 0 & $-M_{2}$ & $M_{2}$ & $M_{1}$ & $M_{1}$ & $L_{s}$ \\
\hline
\end{tabular}

The total stator inductance matrix $\mathrm{L}$ is thus the cosine term in (1) plus the above constant matrix $\underline{L}_{\text {const }}$, where the constants $L_{s}, M_{1}$, and $M_{2}$ are defined below.

$$
\begin{aligned}
& L_{s}=l_{s}+M_{A} \\
& M_{1}=m_{1}+M_{A} \cos (2 \pi / 3) \\
& M_{2}=m_{2}+M_{A} \cos (\pi / 6)
\end{aligned}
$$

The quantity $1_{\mathrm{s}}$ is the leakage inductance of a stator coil, and $\mathrm{M}_{\mathrm{A}}$ is the average value of the self inductance of a coil minus the leakage inductance. The leakage inductances $m_{1}$ and $\mathrm{m}_{2}$ are the stator mutual leakage inductances [2], and they account for that part of the mutual inductance, that does not cross the air gap. These inductances are a supplement to the traditional synchronous machine theory. They originate primarily from the mutual inductance of stator windings sharing the same slots. The stator leakage inductance matrix $\underline{l}$ is thus identical to $\underline{L}_{\text {const }}$ in (2) with all capital letters replaced with lower-case letters.

Any number of coils can be chosen to represent the rotor circuits. In this paper a rotor representation with one field winding $F$, and one damper winding $D$ and $Q$ in each axis is chosen. The self and mutual inductances in the rotor are constants, and the mutual inductances between stator and rotor vary sinusoidally with the instantaneous rotor angle $\theta_{r}$.

\section{B. Model transformation.}

The eigenvectors of the stator inductance matrix were identified, normalized, and arranged in the extended Park's transformation matrix $I_{s}$, which will diagonalize the stator inductance matrix, so that all mutual couplings within the stator itself will disappear.

$$
\underline{T}_{s}(\theta)=\frac{1}{\sqrt{2}} \quad \begin{array}{|l|l|}
\hline \underline{T}_{3 \varphi}(\theta) & \underline{T}_{3 \varphi}(\theta) \\
\hline \underline{T}_{3 \varphi}(\theta-\pi / 6) & -\underline{T}_{3 \varphi}(\theta-\pi / 6) \\
\hline
\end{array}
$$

$\underline{T}_{3 \varphi}(\theta)$ is the well known Park's transformation matrix from $0 \mathrm{dq}$-values to phase values:

$\underline{T}_{3 \varphi}(\theta)=\sqrt{\frac{2}{3}} \cdot$\begin{tabular}{|l|l|l|}
\hline $1 / \sqrt{2}$ & $\cos (\theta)$ & $\sin (\theta)$ \\
\hline $1 / \sqrt{2}$ & $\cos (\theta-2 \pi / 3)$ & $\sin (\theta-2 \pi / 3)$ \\
\hline $1 / \sqrt{2}$ & $\cos (\theta-4 \pi / 3)$ & $\sin (\theta-4 \pi / 3)$ \\
\hline
\end{tabular}

The total transformation matrix $\mathrm{T}$ can now be formed with $\underline{T}_{s}$ as the upper left part of the matrix, and a unit matrix $\underline{U}$ as the lower right part. The rest of the matrix has zeroes in all positions.

$$
\underline{T}=\begin{array}{|l|l|}
\hline \underline{T} & \underline{0} \\
\hline \underline{0} & \underline{U}_{3} \\
\hline
\end{array}
$$

After including the rotor circuits in the inductance matrix, a trivial but cumbersome matrix-multiplication with subsequent trigonometric reductions yields the transformed inductance matrix $\underline{L}_{d}=\underline{T}^{t} \underline{L} \underline{T}$,

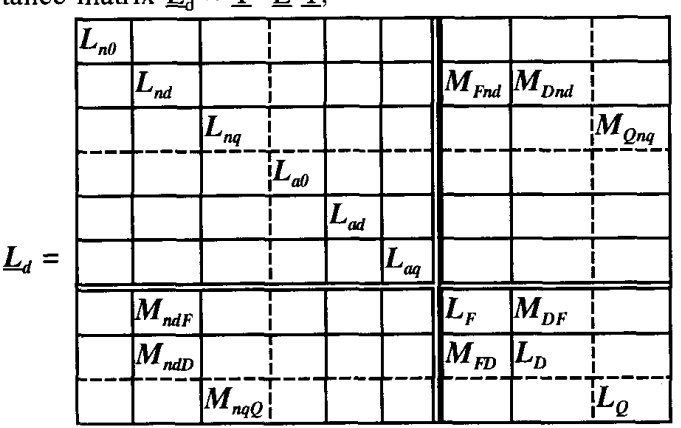

where the stator inductances are expressed using the constants below:

$$
\begin{array}{ll}
L_{n d}= & L_{s}-M_{1}+\sqrt{3} M_{2}+3 M_{B} \\
L_{n q}= & L_{s}-M_{1}+\sqrt{3} M_{2}-3 M_{B} \\
L_{a d}=L_{a q}= & L_{s}-M_{1}-\sqrt{3} M_{2} \\
L_{n 0}=L_{a 0}= & L_{s}+2 M_{1}
\end{array}
$$

As can be seen, the special advantage of this extended Park's transformation is that it transforms the machine stator into a circuit where only one stator coil in each axis links the rotor. The indices (na-0dq) are explained at the end of this section.

Using (3)-(5) and the auxiliary constants:

$$
\begin{aligned}
& M_{d}=3\left(M_{A}+M_{B}\right) \\
& M_{q}=3\left(M_{A}-M_{B}\right) \\
& l_{n}=l_{s}-m_{l}+\sqrt{3} m_{2} \\
& l_{a}=l_{s}-m_{l}-\sqrt{3} m_{2} \\
& l_{n}=i_{s}+2 m_{l}
\end{aligned}
$$

the expressions (10)-(13) can be simplified into:

$$
\begin{array}{ll}
L_{n d}= & l_{n}+M_{d} \\
L_{n q}= & l_{n}+M_{q} \\
L_{a d}=L_{a q}= & l_{a} \\
L_{n \theta}=L_{a 0}= & l_{0}
\end{array}
$$

The following set of matrix equations describe the machine 
behaviour under steady-state, as well as under dynamic and transient conditions.

$$
\begin{aligned}
& \underline{\lambda}_{d}=\underline{L}_{d} \underline{\underline{i}}_{d} \\
& \underline{\underline{v}}_{d}=\underline{R} \underline{i}_{d}+\omega\left(1 / \omega \underline{T}^{t} p \underline{T}\right) \underline{\lambda}_{d}+p \underline{\lambda}_{d} \\
& \tau_{\text {air }}=\underline{i}_{d}^{t}\left(1 / \omega \underline{T}^{t} p \underline{T}\right) \underline{\lambda}_{d} \\
& p \theta=\omega \\
& J p \omega=\tau_{\text {air }}-\tau_{\text {load }}
\end{aligned}
$$

where the speed voltage term $\left(1 / \omega T^{t} p T\right)$ is:

$1 / \omega \underline{T}^{t} p \underline{T}=$

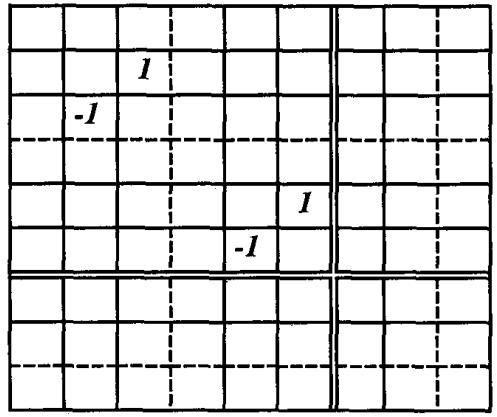

An examination of the matrix equations (23)-(27), together with the matrices (9) and (28), show that the transformation has split the machine equations into two Odq systems respectively called the normal system (indices n0, nd and nq) and the anti system (indices a0, ad and aq). The names 'normal' and 'anti' are chosen since the currents in the normal system support each other thereby creating a normal rotational field in the air gap, and since the currents in the anti system oppose each other, thereby only leaving leakage fluxes in the machine stator.

Note that the equations for the normal system are completely identical to the equations of a standard 3-phase synchronous machine. All modelling techniques (rotor modelling, representation of saturation, parameter identification etc.) known from 3-phase synchronous machine modelling can therefore be used directly without any modifications.

\section{MACHINE PARAMETERS.}

With a machine model now derived the next problem is to get parameters for the model. Preferably these should be determined from the standard data set supplied by the manufacturer. Only the d-axis parameters are determined here, the $\mathrm{q}$-axis parameters can be determined likewise.

The rotor circuit base values have been selected, so that the equivalent circuit (fig.3) of the machine nd-axis will be galvanically coupled.

Using Laplace-domain equations it can be shown that the operational inductance of this circuit is:

$$
L_{n d}(s)=L_{n d} \frac{1+K_{1} s+K_{2} s^{2}}{1+K_{3} s+K_{4} s^{2}}
$$

where the $\mathrm{K}_{\mathrm{x}}$ constants are defined as:

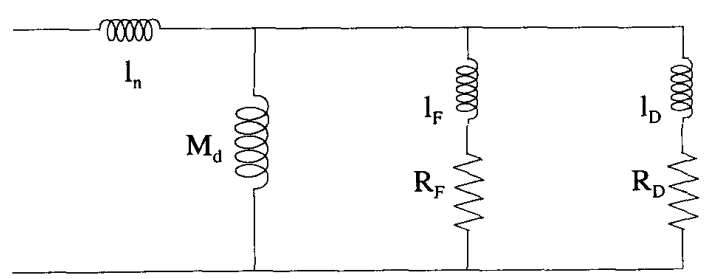

Fig. 3. nd-axis equivalent diagram.

$$
\begin{gathered}
K_{1}=T_{D}+T_{F}+\left(\frac{1}{R_{D}}+\frac{1}{R_{F}}\right) \frac{M_{d} l_{n}}{L_{n d}} \\
K_{2}=T_{D} T_{F}+\left(\frac{T_{F}}{R_{D}}+\frac{T_{D}}{R_{F}}\right) \frac{M_{d} l_{n}}{L_{n d}} \\
K_{3}=T_{D}+T_{F}+\left(\frac{1}{R_{D}}+\frac{1}{R_{F}}\right) M_{d} \\
K_{4}=T_{D} T_{F}+\left(\frac{T_{F}}{R_{D}}+\frac{T_{D}}{R_{F}}\right) M_{d}
\end{gathered}
$$

and where the leakage time constants are defined as:

$$
\begin{aligned}
& T_{D}=l_{D} / R_{D} \\
& T_{F}=l_{F} / R_{F}
\end{aligned}
$$

According to [3] the manufacturer must supply the following standard data set for a 3-phase synchronous machine:

$$
\mathrm{R}_{s}, \mathrm{x}_{1}, \mathrm{x}_{0}, \mathrm{x}_{\mathrm{d}}, \mathrm{x}_{\mathrm{q}}, \mathrm{x}_{\mathrm{d}}{ }^{\prime}, \mathrm{x}_{\mathrm{d}}{ }^{\prime \prime}, \mathrm{x}_{\mathrm{q}}{ }^{\prime \prime}, \mathrm{T}_{\mathrm{d}}{ }^{\prime}, \mathrm{T}_{\mathrm{d}}{ }^{\prime \prime}, \mathrm{T}_{\mathrm{q}}{ }^{\prime \prime}
$$

All data are assumed to have been obtained in a non-saturated condition. Saturation is to be included later on in the machine main reactances $M_{d}$ and $M_{q}$, as these are the only reactances which are seriously subject to saturation.

Since the machine under consideration in this paper is a synchronous machine with two 3-phase systems, all tests are assumed to have been performed with both 3-phase systems connected, being respectively short-circuited or open-circuited, whenever [3] requires this to be the case for the 3phase machine.

According to [4] the d-axis open-circuit time constants $T_{d 0}{ }^{\prime}$ and $\mathrm{T}_{\mathrm{d} 0}$ " can be obtained by solving the following two coupled equations (36)-(37).

$$
\begin{gathered}
T_{d 0}^{\prime}+T_{d 0}^{\prime \prime}=\frac{x_{d}}{x_{d}^{\prime}} T_{d}^{\prime}+\left(1-\frac{x_{d}}{x_{d}^{\prime}}+\frac{x_{d}}{x_{d}^{\prime \prime}}\right) T_{d}^{\prime \prime} \\
T_{d 0}^{\prime} T_{d 0}^{\prime \prime}=T_{d}^{\prime} T_{d}^{\prime \prime x_{d}} \\
x_{d}^{\prime \prime}
\end{gathered}
$$

The equations (36)-(37) actually apply to 3-phase machines, but as explained in the end of section II. $B$ they can be used directly without any modifications due to the special transformation. 
By multiplying all reactances with the machine base impedance $\mathrm{Z}_{\text {base }}$, and dividing with the rated electric angular velocity $\omega$, the corresponding inductances in physical values are calculated.

$$
\begin{aligned}
& L_{n d}=x_{d} Z_{\text {base }} / \omega \\
& l_{n}=x_{l} Z_{b a s e} / \omega
\end{aligned}
$$

Now the operational inductance in the nd-axis can be expressed as:

$$
L_{n d}(s)=L_{n d} \frac{\left(1+T_{d}^{\prime} s\right)\left(1+T_{d}^{\prime \prime} s\right)}{\left(1+T_{d o}^{\prime} s\right)\left(1+T_{d o}^{\prime \prime} s\right)}=L_{n d} \frac{1+\left(T_{d}^{\prime}+T_{d}^{\prime \prime}\right) s+T_{d}^{\prime} T_{d}^{\prime \prime} s^{2}}{1+\left(T_{d 0}^{\prime}+T_{d 0}^{\prime \prime}\right) s+T_{d o}^{\prime} T_{d o}^{\prime \prime} s^{2}}
$$

As stated in (19) the total nd-axis inductance $L_{n d}$ in steadystate is the sum of the stator leakage inductance $l_{n}$ and the mutual inductance $\mathrm{M}_{\mathrm{d}}$. Thus:

$$
L_{n d}=l_{n}+M_{d} \Leftrightarrow M_{d}=L_{n t} \cdot l_{n}
$$

A comparison of the two above expressions (29) and (40) for $\mathrm{L}_{\mathrm{nd}}(\mathrm{s})$ shows, that the following relations must apply:

$$
\begin{aligned}
& K_{I}=T_{d}^{\prime}+T^{\prime \prime}{ }_{d} \\
& K_{2}=T_{d}^{\prime} T_{d{ }^{\prime}}^{\prime \prime} \\
& K_{3}=T_{d \theta}^{\prime}+T_{d \theta}^{\prime \prime} \\
& K_{4}=T_{d \theta}^{\prime} T_{d \theta}^{\prime \prime}{ }_{d \theta}
\end{aligned}
$$

Manipulating (30)-(33) and (42)-(45) makes it possible to reduce them into (46)-(49), where (46)-(47) only contain the unknown quantities $T_{F}$ and $T_{D}$. The equations (46)-(47) are easily solved in the same way as (36)-(37), and with the known values of $T_{F}$ and $T_{D}$ the two remaining equations (48)-(49) are a set of linear equations with respect to $R_{F}^{-1}$ and $R_{D}^{-1}$, which is simple to solve.

$$
\begin{gathered}
T_{D}+T_{F}=\frac{L_{n d}}{M_{d}}\left(T_{d}^{\prime}+T_{d}^{\prime \prime}\right)-\frac{l_{n}}{M_{d}}\left(T_{d 0}^{\prime}+T_{d 0}^{\prime \prime}\right) \\
T_{D} T_{F}=\frac{L_{n d}}{M_{d}}\left(T_{d}^{\prime} T_{d}^{\prime \prime}\right)-\frac{l_{n}}{M_{d}}\left(T_{d 0}^{\prime} T_{d 0}^{\prime \prime}\right) \\
\frac{1}{R_{D}}+\frac{1}{R_{F}}=\frac{L_{n d}}{M_{d}^{2}}\left(T_{d 0}^{\prime}+T_{d 0}^{\prime \prime}-T_{d}^{\prime}-T_{d}^{\prime \prime}\right) \\
\frac{T_{F}}{R_{D}}+\frac{T_{D}}{R_{F}}=\frac{L_{n d}}{M_{d}^{2}}\left(T_{d 0}^{\prime} T_{d 0}^{\prime \prime}-T_{d}^{\prime} T_{d}^{\prime \prime}\right)
\end{gathered}
$$

The second order equations stated above always have a solution provided the data specified are consistent. If not, this means, that no set of model parameters exist for this equivalent diagram (fig.3) with exact correspondence to the machine impedances and time constants.

Now the model parameters have been determined for the nd-axis. The nq-axis parameters follows simply in the same way, and the parameters for the zero sequence axes no and a0 are easily determined from the zero sequence impedance.

Thus the only problem left is to obtain parameters for the ad and the aq axes. At this point it must be noted, that since the standard data sets are defined for 3-phase machines, these data do not contain any information regarding the coupling between the two 3-phase systems (i.e. the factor $\mathrm{m}_{2}$ ). It is therefore necessary to make an assumption if standard machine data are to be used.

A reasonable assumption is, that the ratio between $m_{1}$ and $m_{2}$ is approximately the same as the ratio between the $M_{A}$ terms in (4)-(5); i.e.:

$$
m_{2}=m_{1} \cos (\pi / 6) / \cos (2 \pi / 3)=-\sqrt{3} m_{I}
$$

This is a reasonable assumption since the ratio between the $\mathrm{M}_{\mathrm{A}}$ terms is determined by the geometrical configuration, and the same geometry applies to the mutual leakage inductances. The consequence of this assumption is that the anti system inductance is equal to the zero sequence inductance.

$$
l_{a}=l_{s}-m_{1}-\sqrt{3} m_{2}=l_{s}+2 m_{1}=l_{0}
$$

Preferably a simple standard test should be developed and specified to determine $l_{\mathrm{a}}$ exactly.

\section{CONVERTER MODEL.}

\section{A. Converter description.}

The six-pulse AC-DC converter (fig.4) is a well known thyristor configuration, for which the $\mathrm{AC}$ side steady-state conditions are described by the following set of equations [5]. These equations are based on an assumption of an infinite DC circuit inductance; i.e. a constant DC current. This phasor model is used in a variety of simulation programs.

$$
\begin{gathered}
u=\arccos \left(\cos (\alpha)-\frac{\sqrt{2} I_{D C} \omega L_{c o m}}{U_{c o m}}\right)-\alpha \\
\tan \left(\varphi_{t o t}\right)=\frac{2 u+\sin (2 \alpha)-\sin (2(\alpha+u))}{\cos (2 \alpha)-\cos (2(\alpha+u))} \\
I_{1}=I_{D C} \frac{\sqrt{6}}{\pi} \frac{\sqrt{(\cos (2 \alpha)-\cos (2(\alpha+u)))^{2}+(2 u+\sin (2 \alpha)-\sin (2(\alpha+u)))^{2}}}{4(\cos (\alpha)-\cos (\alpha+u))} \\
I_{n}=I_{D C} \frac{\sqrt{6}}{\pi} \frac{F_{n}}{2 n(\cos (\alpha)-\cos (\alpha+u))}
\end{gathered}
$$

where:

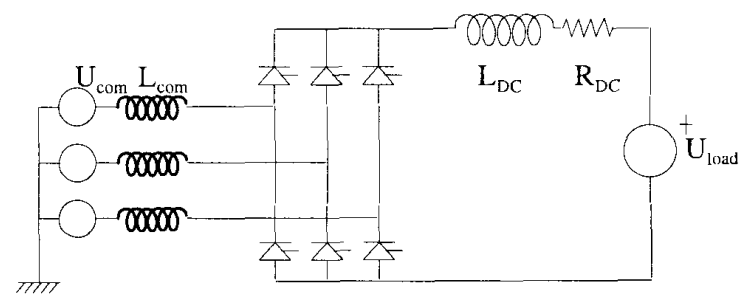

Fig. 4. Six-pulse AC-DC converter. 


$$
F_{n}=\frac{e^{-j(n+1) \alpha}-e^{-j(n+1)(\alpha+u)}}{n+1}-\frac{e^{-j(n-1) \alpha}-e^{-j(n-1)(\alpha+u)}}{n-1}
$$

and where the phase of $\underline{F}_{n}$ is referred to the respective commutating voltage $U_{c o m}$. The quantity $\alpha$ is the ignition delay angle, $u$ is the commutation overlap angle, and $\varphi_{\text {tot }}$ is the power angle between the fundamental frequency current $I_{1}$ and the commutating voltage $\mathrm{U}_{\text {com }}$.

Likewise the following steady state relation applies on the DC side:

$$
\begin{gathered}
U_{D C}-R_{c o m} I_{D C}=R_{D C} I_{D C}+U_{\text {load }} \\
U_{D C}=\frac{3 \sqrt{2}}{\pi} U_{c o m} \cos (\alpha) \quad \text { and } \quad R_{c o m}=\frac{3}{\pi} \omega L_{c o m}
\end{gathered}
$$

Section IV.D shows how to determine the commutating inductance $\mathrm{U}_{\text {com }}$, and section V.A and V.B shows, how to determine the commutation inductances.

\section{B. Fundamental frequency model.}

The converter fundamental frequency conditions are as shown in the vector diagram in fig.5 with $U_{\text {com }}, I_{1}$ and $\varphi_{\text {tot }}$. The phasor $U_{\text {term }}$ is the converter fundamental frequency terminal voltage. When seen from the infinite bus $\left(U_{\text {com }}\right)$ the converter could be replaced with a Thevenin equivalent with the (variable) Thevenin inductance $\mathrm{L}_{\mathrm{Th}}$ and the Thevenin voltage $\underline{\mathrm{U}}_{\mathrm{Th}}$.

The Thevenin voltage $\underline{\mathrm{U}}_{\mathrm{Th}}$ is determined as the active part of the commutating voltage $\underline{U}_{c o m}$; i.e. $\underline{U}_{T h}$ is the projection of $\underline{\mathrm{U}}_{\mathrm{com}}$ in the direction of $\underline{\mathrm{I}}_{1}$.

$$
\begin{aligned}
& U_{T h}=\underline{U}_{\text {com, act. }}=\underline{U}_{\text {com }} \cos \left(\varphi_{t o t}\right) \exp \left(-j \varphi_{t o t}\right) \\
& L_{T h}=\sin \left(\varphi_{t o t}\right) U_{\text {com }} /\left(\sqrt{3} \omega I_{1}\right) .
\end{aligned}
$$

This Thevenin equivalent is however supposed to be connected directly to the infinite bus behind the commutating inductance $\mathrm{L}_{\text {com }}$, but in any realistic simulation this node is not available. Instead the only available node is the converter terminal. Therefore the converter equivalent must be connected here.

This leads to the problem that the converter equivalent inductance must be adjusted so that there still is the correct Thevenin inductance between the (imaginary) infinite bus, behind the commutation inductance, and the converter Thevenin source. This leads to the inductance $\mathrm{L}_{\mathrm{con}}$ of the converter equivalent.

$$
L_{c o n}=L_{T h}-L_{c o m}
$$

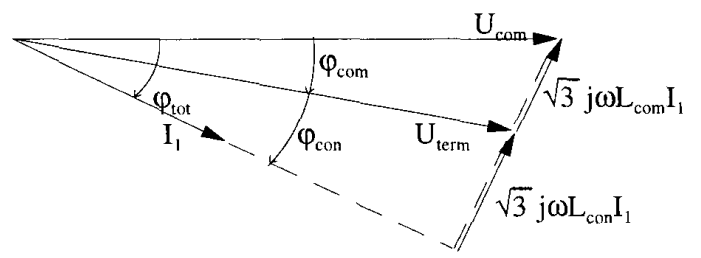

Fig. 5. Fundamental frequency phasor diagram.
Thus a Thevenin equivalent, with the Thevenin voltage $U_{T h}$ and the inductance $\mathrm{L}_{\mathrm{con}}$, will inject the same fundamental frequency currents into the network as the actual converter.

\section{Representation of harmonics.}

The general flaw with this model, as well as with all other converter models that do not include a physical model of each thyristor, is that it only includes the fundamental frequency terms.

If however harmonic currents with the same amplitude and phase as the converter harmonic currents are injected at the converter terminals into the commutation inductance and thus into the network, then the harmonic effects of the converter will be represented by this current injection. This scheme can be used to include harmonics in the model described above.

Now if a harmonic current source is connected to the converter terminals, then these currents will be split between the commutating inductance $\mathrm{L}_{\text {com }}$ and the converter equivalent inductance $\mathrm{L}_{\text {con }}$ according to the current division ratio between these inductances. This happens regardless of the commutating voltage $\underline{\mathrm{U}}_{\mathrm{com}}$ and the converter Thevenin voltage $\underline{\mathrm{U}}_{\mathrm{Th}}$, since these both are fundamental frequency voltage sources and thus constitute a short-circuit to ground for all harmonics. See fig. 6 for the total equivalent diagram.

The harmonics can therefore be included in the converter model by injection of the harmonic currents (55) rescaled by the harmonic scaling factor harmfact, which is the reciprocal of the current division ratio.

$$
\text { harmfact }=\left(L_{c o m}+L_{c o n}\right) / L_{c o n}
$$

This harmonic scaling factor ensures that exactly the correct amount of harmonic currents are injected into the network. The surplus is short circuited to ground through the converter fundamental frequency equivalent.

In phasor domain simulation programs it is necessary to include each harmonic individually, and therefore it is possible to decide exactly how many harmonics to include. In real time domain simulation programs this is also possible, but here another possibility is to include all harmonics in one single operation.

This is possible since it is possible to determine the exact line current with all harmonics as well as the fundamental frequency current. The difference between these two currents must then be all the harmonic currents (fig.7), and

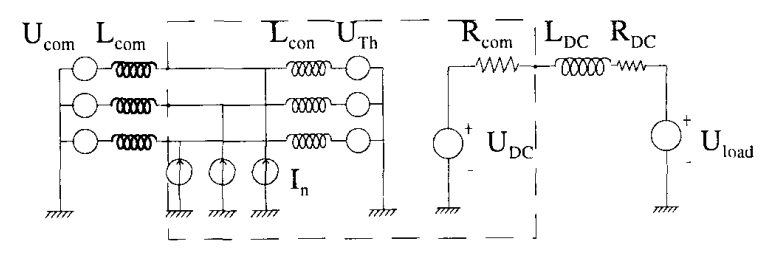

Fig. 6. Converter equivalent diagram. 


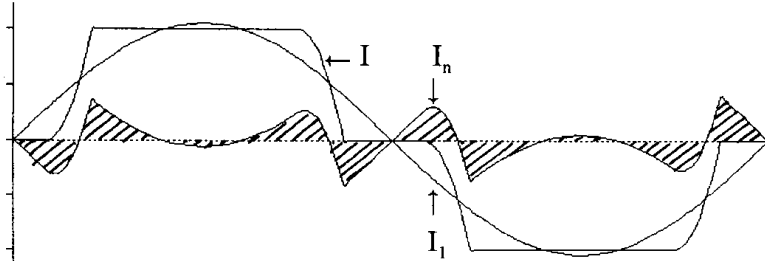

Fig. 7. Converter line, harmonic, and fundamental frequency currents.

these currents must be rescaled with the harmonic scaling factor harmfact.

In a simulation of the motor drive in fig. 1 this converter model must be used 4 times; once for each converter.

\section{Commutating voltage.}

The model described above represents the converter including any chosen number of harmonics. An evaluation of the equations shows, that one of the most important values to be known is the commutating voltage $\underline{U}_{\text {com }}$. Fig. 5 shows that the following relation must apply:

$$
U_{\text {com }} \cos \left(\varphi_{t o t}\right)=U_{t e m} \cos \left(\varphi_{\text {con }}\right)
$$

It is straight-forward to determine $\underline{U}_{\text {term }}$ - and thereby $\underline{U}_{\text {com }}$ using (63) - if the model is implemented in a phasor domain simulation program, since the voltage phasor is a variable which is inherently available regardless whether there are any harmonics included in the model or not. If however the model is implemented in a real time domain simulation program then it is necessary to perform some sort of voltage detection in order to determine the voltage phasor. This can of course be performed at the converter terminals, but if harmonics are included in the model then the phasor detection will be troubled by the presence of the harmonics.

For this reason it is desirable to apply the voltage detection directly to the commutating voltage, but as already explained this is not possible, since this voltage is at an imaginary node behind the commutation inductances. Fortunately there is a small work-around for this problem.

The insertion of two inductances in series - one with minus the estimated commutating inductance $\mathrm{L}_{\mathrm{com}}^{\prime}$ and the other with plus this value - between the converter equivalent and the converter terminal (see fig.8) does not change the behaviour of the network, since this detection circuit is a

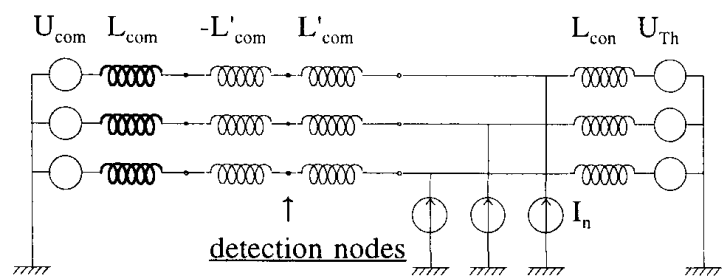

Fig. 8. Converter AC side equivalent diagram with detection circuit. perfect short circuit, but now the voltage at the middle point of this circuit is identical to the commutating voltage provided the value of the estimated commutating inductance is correct. This is a pure fundamental frequency voltage, which is easy to detect.

A secondary advantage with this detection node is that it can be used to verify that the estimated commutating inductance $L_{c o m}^{\prime}$ is correct. This is important since this value is used in the converter equivalent. If the estimated commutating inductance is wrong, and if harmonics are included in the simulation, then the voltage at the detection node will not be purely fundamental frequency. Thus by monitoring the harmonic contents at this node it can be determined whether the estimated commutating inductance is correct.

\section{COMMUTA TING INDUCTANCES.}

\section{A. Network commutating inductance.}

The network commutating inductances are determined by the network and primarily by the transformer that supplies the converter (fig.1). The transformer leakage inductance (the short circuit impedance $X_{s h}$ ) is a good measure for the network commutating inductance even though the network behind the transformer also accounts for a small part of the commutating inductance.

\section{B. Synchronous machine commutating inductance.}

Now the $2 \times 3$-phase synchronous machine commutating inductance must be determined from the machine parameters. The easiest way to do this is to recall, that the commutation process is a subtransient process, so it must be possible to determine the commutation inductance matrix $\underline{L}_{\mathrm{com}}$ in phase values from the subtransient inductance matrix $l^{\text {" in the rotor }}$ reference frame by transforming this matrix back to phase values using the extended Park's transformation.

$$
\underline{L}_{c o m}=\underline{T}_{r}\left(\theta_{r}\right) \underline{l}^{\prime \prime} \underline{T}^{t}\left(\theta_{r}\right)
$$

where:

$$
\underline{l}^{\prime \prime}=\text { DiagonalMatrix }\left[\left\{l_{p}, l_{n d}^{\prime \prime}, l_{n q}^{\prime \prime}, l_{t p} l_{w}, l_{d}\right\}\right]
$$

A calculation of $\underline{L}_{\text {com }}$ shows, that the self and mutual inductances of e.g. phase al and bl is:

$$
\begin{aligned}
& l_{a 1}=\left(l_{b}+l_{a}+l_{a v r}{ }^{\prime \prime}+l_{d e v}{ }^{\prime \prime} \cos \left(2 \theta_{r}\right)\right) / 3 \\
& l_{b I}=\left(l_{0}+l_{a}+l_{a v r}{ }^{\prime \prime}+l_{d e v}{ }^{\prime \prime} \cos \left(2 \theta_{r}-4 \pi / 3\right)\right) / 3 \\
& l_{a l b I}=\left(2 l_{0}-l_{a}-l_{a v r}{ }^{\prime \prime}+2 l_{d e v}{ }^{\prime \prime} \cos \left(2 \theta_{r}-2 \pi / 3\right)\right) / 6
\end{aligned}
$$

where:

$$
\begin{aligned}
& l_{a v v}{ }^{\prime \prime}=1 / 2\left(l_{n d}{ }^{\prime \prime}+l_{n q}{ }^{\prime}\right) \\
& l_{d e v}{ }^{\prime \prime}=1 / 2\left(l_{n d}{ }^{\prime \prime}-l_{n q}{ }^{\prime \prime}\right)
\end{aligned}
$$

For any given rotor angle $\theta_{\mathrm{r}}$ the instantaneous commutation inductance $\mathrm{L}_{\text {com }}$ between phase al and bl can now be determined according to the following expression.

$$
\begin{aligned}
L_{c o m, a l b 1} & =1 / 2\left(l_{a 1}+l_{b 1}-2 l_{a l b l}\right) \\
& =1 / 2\left(l_{a}+l_{a v r}{ }^{\prime \prime}+l_{d e v}{ }^{\prime \prime} \cos \left(2 \theta_{r}+\pi / 3\right)\right)
\end{aligned}
$$

It is noted that the anti sequence inductance $l_{a}$ appear in 
Line voltage $U_{\text {alc1 }}$ (V) \& Phase current $I_{a 1}$ (A)

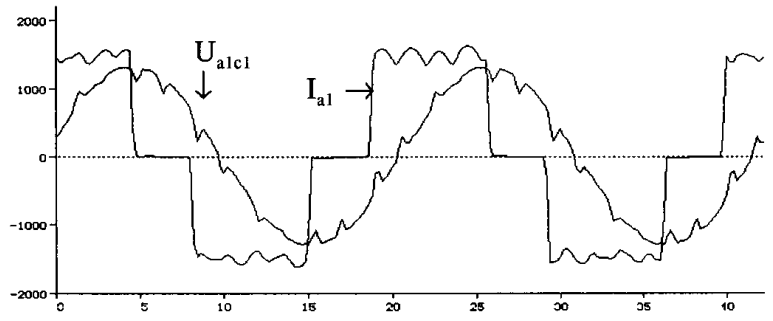

Fig. 9. Measured voltage and current. Time (ms)

Line voltage $U_{a 1 c l}(V) \& \quad$ Phase current $I_{a 1}(A)$

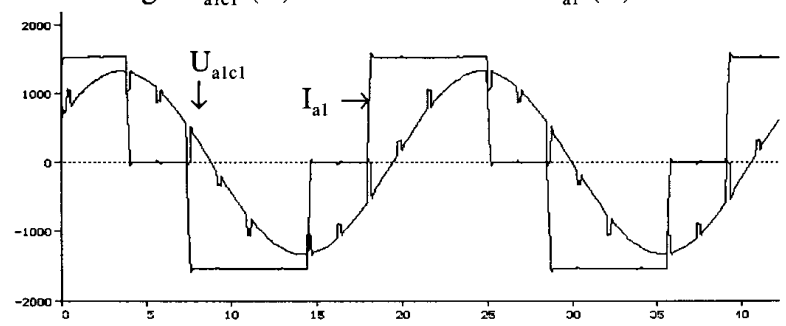

Fig. 10. Simulated voltage and current with all harmonics.

Time (ms)

Line voltage $U_{a \mid c l}$ (V) \& Phase current $I_{a 1}$ (A)

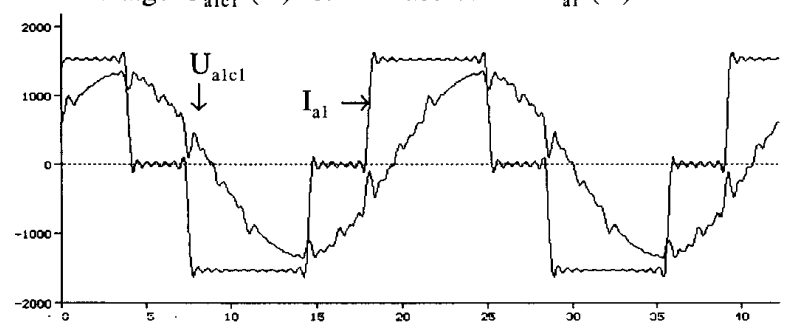

Fig. 11. Simulated voltage and current with harmonics up to $37^{\text {th }}$

the commutation inductance expression. This was to be expected since the anti sequences are excited during commutation. Since the amplitude of the sinusoidal variation in (71) is small compared to the constant terms for non-salient pole machines, the sinusoidal part is disregarded in the following.

\section{Vi. PRACTICAL ReSUltS.}

A set of current and voltage curves were measured at a 7.2 MW feed water pump motor at the Fynsvaerket Power Plant in Odense, Denmark (fig.9). Because of a limited bandwidth in the voltage measuring equipment, high frequency terms in the voltage peaks are not visible.

The synchronous machine model and the converter phasor model was implemented in EMTP (Electro Magnetic Tran- sients Program). Shown here are two simulations of the measured steady-state (fig. $10 \& 11$ ) with respectively all harmonics included, and harmonics up to the $37^{\text {th }}$ included. Except for the missing ripple at the simulated currents - due to the fact that the phasor model is based on an assumption of constant DC current - the simulations show within a margin of $4 \%$ the same voltage and current traces as the measured curves when considering amplitude, phase, position of voltage peaks, and the number of harmonics included. It seems therefore that the models are sufficiently good representations of the machine and the converter, and that the EMTP implementation works.

\section{CONCLUSIONS.}

A model of the $2 \times 3$-phase synchronous machine has been developed and tested, and a consistent parameter identification procedure based on standard manufacturer data has been derived. A phasor model of the 6-pulse line-commutated AC-DC converter with representation of any number of AC side characteristic harmonics has been developed. The models have been implemented in EMTP, and have been verified in the steady-state by comparing measured and simulated results from a 7.2 MW feed water pump motor.

\section{REFERENCES.}

[1] Paul C. Krause: 'Analysis of Electric Machinery', McGraw-Hill 1986, ISBN 0-07-035436-7.

[2] H. Bissig, K. Reichert: 'The 2x3-phase Converter Fed Synchronous Machine - Modelling, Simulation and Practical Results', Conference on Synchronous Machines SM100, Zurich, Switzerland, 27-29 August 1991, vol. 1, pp. 320-326.

[3] IEEE Test Procedures for Synchronous Machines (ANSI). Standard 115-1983.

[4] Hermann W. Dommel: 'Electromagnetic Transients Program Reference Manual (EMTP Theory Book)', Bonneville Power Administration, Portland, Oregon 97208, U.S.A.

[5] E.W.Kimbark: 'Direct Current Transmission', John Wiley \& Sons, ISBN 0-471-47580-7.

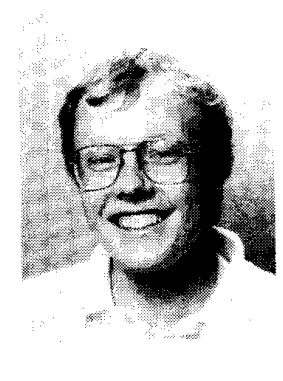

Hans Knudsen was born in Denmark on June 2, 1964. He received his M.Sc.E.E. at the Technical University of Denmark in 1991. He is currently employed by NESA / SK Power Company, where he is performing a Ph.D. study concerning converter-fed 6-phase synchronous machines in cooperation with ELSAMPROJEKT Power Station Engineering, and the Electric Power Engineering Department at the Technical University of Denmark. The project is sponsored by the Academy of Technical Sciences (ATV), Denmark. 